\title{
Modeling multiple failures of composite box beams used in wind turbine blades
}

\author{
Chen, Xiao; Tang, Jing; Yang, Ke
}

Published in:

Composite Structures

Link to article, DOI:

10.1016/j.compstruct.2019.03.018

Publication date:

2019

Document Version

Peer reviewed version

Link back to DTU Orbit

Citation (APA):

Chen, X., Tang, J., \& Yang, K. (2019). Modeling multiple failures of composite box beams used in wind turbine blades. Composite Structures, 217, 130-142. https://doi.org/10.1016/j.compstruct.2019.03.018

\section{General rights}

Copyright and moral rights for the publications made accessible in the public portal are retained by the authors and/or other copyright owners and it is a condition of accessing publications that users recognise and abide by the legal requirements associated with these rights.

- Users may download and print one copy of any publication from the public portal for the purpose of private study or research.

- You may not further distribute the material or use it for any profit-making activity or commercial gain

- You may freely distribute the URL identifying the publication in the public portal

If you believe that this document breaches copyright please contact us providing details, and we will remove access to the work immediately and investigate your claim. 


\section{Accepted Manuscript}

Modeling multiple failures of composite box beams used in wind turbine blades

Xiao Chen, Jing Tang, Ke Yang

PII:

S0263-8223(18)34060-1

DOI: https://doi.org/10.1016/j.compstruct.2019.03.018

Reference: COST 10746

To appear in:

Composite Structures

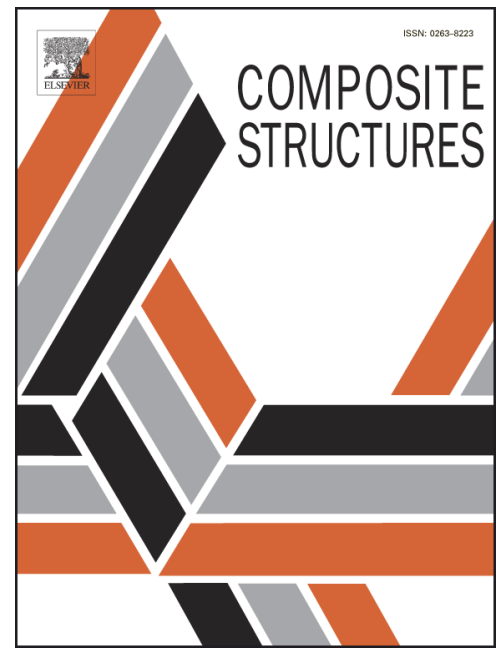

Received Date: $\quad 8$ November 2018

Revised Date: $\quad 16$ January 2019

Accepted Date: $\quad 1$ March 2019

Please cite this article as: Chen, X., Tang, J., Yang, K., Modeling multiple failures of composite box beams used in wind turbine blades, Composite Structures (2019), doi: https://doi.org/10.1016/j.compstruct.2019.03.018

This is a PDF file of an unedited manuscript that has been accepted for publication. As a service to our customers we are providing this early version of the manuscript. The manuscript will undergo copyediting, typesetting, and review of the resulting proof before it is published in its final form. Please note that during the production process errors may be discovered which could affect the content, and all legal disclaimers that apply to the journal pertain. 


\title{
Modeling multiple failures of composite box beams used in wind turbine blades
}

\author{
Xiao Chen ${ }^{a *}$, Jing Tang ${ }^{b, c}$, Ke Yang ${ }^{b, c}$
}

\author{
a. Department of Wind Energy, Technical University of Denmark, Frederiksborgvej 399, 4000 Roskilde, Denmark \\ b. Institute of Engineering Thermophysics, Chinese Academy of Sciences, Beijing 100190, China \\ c. University of Chinese Academy of Sciences, Beijing 100190, China \\ *Corresponding author: Xiao Chen xiac@dtu.dk
}

\begin{abstract}
:
Large composite structures, such as composite wind turbine blades, may exhibit multiple failure modes that challenge the modeling strategies and methodologies designers adopt in finite element (FE) analysis. This study develops a comprehensive and general FE modeling method to simulate interactive failure process of composite box beams used in wind turbine blades. The composite box beams are the primary loading-carrying members and could show different failure modes due to competing failure mechanisms. A continuumdamage mechanics based progressive failure analysis approach is developed in three-dimensional stress/strain domain to simulate failure behavior of the box beams. Structural nonlinearities associated with geometry, materials and contact are included. The material failures considered in this study are composite failure with three material failure modes, foam core crushing and adhesive failure. The in-plane shear stress versus strain relation of unidirectional composites is included in the material damage model. Comprehensive comparisons are made between numerical simulations and experimental observations with respect to strain response, ultimate loads, failure modes and failure progress. The modeling approach is found to be capable of predicting both strength and failure of box beams with reasonable accuracy and it exhibits great potential to predict failure response of composite wind turbine blades.
\end{abstract}

\section{Keywords:}

fracture; debonding; competing failure mechanisms; progressive failure; delamination; shear nonlinearity; foam crushing

\section{Introduction}

Box beams are typical load-carrying members in composite structures such as wind turbine blades. The box beams in wind turbine blades often consist of four parts, which include two monolithic composite laminates, i.e., spar caps and two sandwich laminates, i.e., shear webs. The four parts can be manufactured separately and then they are adhesively bonded together to form a box-shaped beam. The composite box beam determines the overall structural stiffness and ultimate strength of a large portion of blades in the spanwise direction. Typical failure modes observed in the box beams used in the wind turbine blades include spar cap delamination, shear web fracture, debonding of adhesive joints, foam core failure, laminate cracks, etc. [1-7]. These failures may occur as a chain of events in the failure process driven by competing failure mechanisms. Understanding the cause and effect of different failures is important for improving structural design. Due to numerous combinations of different structural designs, material properties and load conditions, it is not practical to examine all possible failure modes experimentally. It is necessary to develop a general numerical modeling approach that can accurately predict several typical failure modes and their interaction in one single simulation, which could enable a better understanding of failure mechanisms of load-carrying box beams and eventually facilitate more efficient blade design.

Modeling failure behavior of composite structures is a challenging task. Multiple structural nonlinearities have to be taken into account in order to predict different failure modes and the failure sequence of composite structures. For wind turbine blades, some examples of structural nonlinearities that might affect their structural failure are illustrated in Figure 1. In general, three categories of structural nonlinearities could exist. They include geometric nonlinearity related to large deformation, brazier effect and buckling phenomenon, contact nonlinearity related to the change of boundary conditions at the loading and supporting points during the loading history and material nonlinearities related to the nonlinear stress-strain relation and the failure of materials. It is noted that material failures can be further divided into several types depending on material failure modes under concern. In this study, the focus is placed on modeling the failures of box beams under bending which has been presented in the previous experimental work [1]. The observed material failures 
include sandwich skin composite failure in the form of delamination and fracture, sandwich core crushing and adhesive joint debonding.

Figure 1. Examples of structural nonlinearities that might be experienced by composite wind turbine blades

A few studies [8,9] have investigated the failure of composite box beams that are made of monolithic composite laminates. In wind turbine blades, composite box beams consist of both monolithic composite laminates and sandwich laminates as well as adhesive joints that connect them. The study on the failure of these composite box beams is rare. A pioneer work has been carried out by Cole et al. [3] and $\mathrm{Yu}$ et al. [4] to study failure modes of composite box beams under flapwise loading in three-point and four-point bending tests. Jensen et al. [10] tested several cross sections of loading-carrying box girders to examine non-uniform ovalization phenomenon and demonstrated a few inventions for structural reinforcement. Puri [11] further reported more tests on the box girder cross section specimens and examined different failure modes. In our previous study [1], experimental work has been carried out to investigate failure response of composite box beams, instead of cross sections, with different designs and under different load conditions. As a continuation of the work, the current study aims to develop a modeling approach to predict failure behavior of the box beams that exhibited multiple failures in the experiment, which helps advance virtual testing techniques of large composite structures.

As such, the major contribution of this study is development and demonstration of a comprehensive and general FE modeling method capable of capturing different failure modes that are typical to composite blade structures in a three-dimensional stress/strain domain. This method integrates modeling techniques that are currently available in the commercial FE software such as the cohesive zone model for adhesive debonding and that are newly developed in this study such as progressive failure analysis of composite laminates in the three-dimensional stress/strain formulation. Both in-plane failure modes, i.e., the fiber-dominant failure and the matrix-dominant failure, and out-of-plane failure mode, i.e., delamination, are modeled based on continuum-damage mechanics approach. In addition, the foam core failure is, to our best knowledge, first reported for blade structures.

Failure simulation can be performed at different scales depending on the objectives of concerned problems. In this study, the failure modeling is carried out at a structural level focusing on failure behavior of box beams associated with multiple structural nonlinearities. The modeling method of geometric details, contact conditions and material damages of the box beams is presented. Comprehensive comparisons between numerical predictions and experimental observations are made with respect to ultimate strength, failure modes and failure process. The failure mechanisms of the box beams are examined taking into account both experimental investigation and numerical simulation. The potential application of the proposed modeling approach to analyzing other composite structures is also addressed in this study.

\section{Description of box beam tests}

To provide relevant contexts of the current study, the previous experimental work [1] is described here briefly. Three-point bending tests were conducted on composite box beams typically used in wind turbine blades under both flapwise and edgewise loading. In total, five box beams with different designs and loading schemes were investigated. In this study, only two specimens, i.e., CB_F2 under flapwise loading and CB_E2 under edgewise loading, are used to present and demonstrate the proposed modeling approach. Two box beams were loaded quasi-statically to failure as shown in Figure 2. The failures, in general, were localized in the loading regions. The primary failure modes identified from the experiments include delamination and fracture of both sandwich skin laminates and spar cap laminates, crushing failure of foam core materials and debonding of adhesive joints. It was also found that local buckling and the Brazier effect affected the failure process of the box beams depending on different loading directions.

Figure 2. Experimental observations and illustration of failures in composite box beams (Experiment [1])

\section{Finite element (FE) modeling approach}


A few numerical modeling techniques are used in this study. The experimental setup is modeled in detail taking into account structural details, the supports and the loading plates of the box beams. Contact conditions are assigned to the matching surfaces which may introduce contact nonlinearity. A damage-mechanics based progressive failure analysis approach is used to model different material failures. The geometric, material and contact nonlinearities are included to predict the nonlinear structural response of the box beams to the final failure. The FE models are created in Abaqus [12] and user subroutines are developed to implement material damage models.

\subsection{Geometric model}

The FE model of the box beam under flapwise loading is shown in Figure 3. It reproduces the experimental setup in detail. Two rigid analytical surfaces are used to model thick arc steel plates to support the box beams assuming their deformation is negligible. Contact surfaces are assigned to the rigid analytical surface and the matching surfaces of composite plates at two support locations, allowing the latter to slide and rotate during the loading. Three loading plates are modeled and they include one steel plate, one wood plate and one rubber plate. Contact surfaces are assigned to their interfaces and enable the change of contact status during the loading. Solid elements C3D8R are used to mesh composites, PVC foam and the loading plates. Cohesive elements COH3D8 are used to mesh adhesive materials. A mesh bias is applied so that finer meshes are generated in the middle region of the box beams and near the loading location to better capture local stresses/strains while keeping the computational cost at a reasonable level.

Figure 3. Geometric model of the box beam under flapwise loading

A prescribed displacement is applied to the top center of the steel plate, resulting in a displacement-controlled loading that facilitates the simulation of the post-peak response. Because both spar caps and shear webs are modeled to be perfectly flat, a geometric imperfection is introduced to initiate the desired out-of-plane deformation that has been observed in the experiment. The geometric imperfection is assumed to have a similar distribution to the first linear buckling mode shape of the box beam, see Appendix 1. A downscaling is applied to the first linear buckling mode shape in such a way that the maximum geometric imperfection is about $0.135 \mathrm{~mm}$, which is $1 \%$ of the total thickness of the shear web. An initial study has been conducted to ensure the small imperfection triggers the desired deformation while does not affect structural strength and failure behavior of the box beam. The geometric model of the box beam under edgewise loading is treated in the same way as that under flapwise loading.

\subsection{Material damage models}

Three materials exhibited failure in the box beams and they are composite materials, PVC foam materials and adhesive materials. In this study, a continuum damage mechanics based progressive failure analysis approach is used to model composite failure at a laminate level in a three-dimensional stress/strain state. The composite failure is divided into two types. One type is the in-plane composite failure which includes the fiber-failure dominant mode and the matrix-failure dominant mode. The other type is the out-of-plane composite failure, or delamination, which is controlled by three through-thickness strain components. For the unidirectional composites, the shear nonlinearity between in-plane shear stress and strain is also incorporated in the composite material model. PVC foam materials used in sandwich shear webs are modeled a crushable material as the foam crushing has been observed as a major failure mode in the test. Adhesive materials are models using the cohesive zone model currently available in Abaqus [12].

\subsubsection{Composite material}

The progressive failure modeling of composite materials is carried out in three steps. The first step is stress analysis to obtain threedimensional stresses and strains; the second step is applying failure criteria to determine the occurrence, or initiation, of material failure and identify material failure mode; the third step is degradation of elastic properties based on the specific material failure mode. The structure is loaded incrementally allowing local stresses to redistribute, new damages to occur and the overall structural integrity to decrease until the ultimate failure of the entire specimen.

The initiation of in-plane composite failure is predicted by the three-dimensional Tsai-Wu failure criterion [13]: 
$f_{T W}=F_{1} \sigma_{11}+F_{2} \sigma_{22}+F_{3} \sigma_{33}+2 F_{12} \sigma_{11} \sigma_{22}+2 F_{13} \sigma_{11} \sigma_{33}+2 F_{23} \sigma_{22} \sigma_{33}+F_{11} \sigma_{11}^{2}+F_{22} \sigma_{22}^{2}+F_{33} \sigma_{33}^{2}+F_{44} \sigma_{23}^{2}+F_{55} \sigma_{13}^{2}+F_{66} \sigma_{12}^{2} \geq 1$

where, $F_{1}=1 / \sigma_{11 t}^{u}+1 / \sigma_{11 c}^{u}, F_{2}=1 / \sigma_{22 t}^{u}+1 / \sigma_{22 c}^{u}, F_{3}=1 / \sigma_{33 t}^{u}+1 / \sigma_{33 c}^{u}$

$$
\begin{aligned}
& F_{12}=-0.5 /\left(\sigma_{11 t}^{u} \sigma_{11 c}^{u} \sigma_{22 t}^{u} \sigma_{22 c}^{u}\right)^{0.5}, F_{13}=-0.5 /\left(\sigma_{11 t}^{u} \sigma_{11 c}^{u} \sigma_{33 t}^{u} \sigma_{33 c}^{u}\right)^{0.5}, F_{23}=-0.5 /\left(\sigma_{22 t}^{u} \sigma_{22 c}^{u} \sigma_{33 t}^{u} \sigma_{33 c}^{u}\right)^{0.5} \\
& F_{11}=1 /\left(\sigma_{11 t}^{u} \sigma_{11 c}^{u}\right), F_{22}=1 /\left(\sigma_{22 t}^{u} \sigma_{22 c}^{u}\right), F_{33}=1 /\left(\sigma_{33 t}^{u} \sigma_{33 c}^{u}\right) \\
& F_{44}=1 /\left(\sigma_{23}^{u}\right)^{2}, F_{55}=1 /\left(\sigma_{13}^{u}\right)^{2}, F_{66}=1 /\left(\sigma_{12}^{u}\right)^{2}
\end{aligned}
$$

and $\sigma_{i j}(i, j=1,2,3)$ is the stress component in the corresponding direction. The subscripts 11,22 and 12 represent longitudinal, transverse and shear directions of the composite ply. The subscripts 13,23 and 33 represent axial shear, transverse shear and normal components in through-thickness direction. The superscript $u$ presents ultimate strength of the material. The subscripts $t$ and $c$ represent tensile and compressive directions, respectively.

Because the Tsai-Wu failure criterion [13], unlike the Hashin criterion [14], does not distinguish the nature of the composite failure. It is necessary to separate different material failure modes so that appropriate material degradation rules can be applied to the specific material failure mode. In this study, the Tsai-Wu failure is divided into two modes as proposed by [15], the one leading to the local softening effect of the composites due to matrix damage and the other leading to more catastrophic failure due to fiber fracture. Eq. (1) is separated into two mode dependent terms which indicate the fiber-dominant failure $f_{f}$ and the matrix-dominant failure $f_{m}$ :

$f_{f}=F_{1} \sigma_{11}+F_{11} \sigma_{11}^{2}$

$f_{m}=f_{T W}-f_{f}$

The mode-separated Tsai-Wu failure criterion is then defined as,

Fiber-dominant failure: $f_{T W} \geq 1$ and $f_{f}>f_{m}$

Matrix-dominant failure: $f_{T W} \geq 1$ and $f_{f} \leq f_{m}$

The occurrence of delamination between two adjacent composite plies is determined by the quadratic strain-based failure criterion with the three through-thickness strain components normalized by their corresponding ultimate strains.

$f_{D L}=\left(\varepsilon_{33 t} / \varepsilon_{33 t}^{u}\right)^{2}+\left(\varepsilon_{13} / \varepsilon_{13}^{u}\right)^{2}+\left(\varepsilon_{23} / \varepsilon_{23}^{u}\right)^{2} \geq 1$

where $\varepsilon_{33 t}, \varepsilon_{13}$ and $\varepsilon_{23}$ are the ultimate stains in the through-thickness tensile direction, the axial shear and transverse shear direction, respectively. Using this failure criterion, it is assumed that through-thickness compression does not contribute to delamination. Elastic and strength properties of composite materials used in this study are shown in Table 1.

\begin{tabular}{|c|c|c|c|c|c|c|c|c|c|}
\hline Composite & $E_{11}$ & $E_{22}$ & $E_{33}$ & $v_{12}$ & $v_{13}$ & $v_{23}$ & $G_{12}$ & $G_{13}$ & $G_{23}$ \\
\hline Unidirectional & 39.0 & 13.0 & 13.0 & 0.205 & 0.205 & 0.349 & $5.4^{*}$ & 3.4 & 3.4 \\
\hline Biaxial & 12.5 & 12.5 & 12.5 & 0.498 & 0.498 & 0.498 & 10.3 & 10.3 & 10.3 \\
\hline \multicolumn{10}{|c|}{ *Initial in-plane shear modulus } \\
\hline \multicolumn{10}{|c|}{ Table 1-b. Stress-based strength properties (MPa) } \\
\hline Composite & $\sigma_{11} \mathrm{u}_{-} \mathrm{t}$ & $\sigma_{11} \mathrm{u}_{-} \mathrm{c}$ & $\sigma_{22} 2_{-}^{\mathrm{u}} \mathrm{t}$ & $\sigma_{22}{ }^{\mathrm{u}}-\mathrm{c}$ & $\sigma_{33^{2}-\mathrm{t}}^{\mathrm{u}}$ & $\sigma_{33^{\mathrm{u}}-\mathrm{c}}$ & $\sigma_{12}{ }^{\mathrm{u}}$ & $\sigma_{13}{ }^{\mathrm{u}}$ & $\sigma_{23}{ }^{\mathrm{u}}$ \\
\hline Unidirectional & 850 & 500 & 38 & 170 & 33 & 170 & 50 & 55 & 45 \\
\hline Biaxial & 160 & 160 & 160 & 160 & 31 & 160 & 241 & 55 & 45 \\
\hline
\end{tabular}

Table 1. Elastic and strength properties of composite materials used in the FE model.

Table 1-a. Elastic constants (modulus unit in GPa, Poisson's ratio unit in 1)

Table 1-c. Through-thickness ultimate strains (\%)

\begin{tabular}{lccc}
\hline Composite & $\varepsilon_{33^{\mathrm{u}}{ }^{\mathrm{t}}}$ & $\varepsilon_{13^{\mathrm{u}}}$ & $\varepsilon_{23}{ }^{\mathrm{u}}$ \\
\hline Unidirectional & 0.21 & 1.1 & 0.81 \\
Biaxial & 1.22 & 1.22 & 1.35 \\
\hline
\end{tabular}


Table 2. Material degradation rule applied to composite materials in this study.

\begin{tabular}{lccccccccc}
\hline Material failure mode & $E_{11}$ & $E_{22}$ & $E_{33}$ & $v_{12}$ & $v_{13}$ & $v_{23}$ & $G_{12}$ & $G_{13}$ & $G_{23}$ \\
\hline No failure & 1 & 1 & 1 & 1 & 1 & 1 & 1 & 1 & 1 \\
Fiber-dominant failure & 0 & 0 & 0 & 0 & 0 & 0 & 0 & 0 & 0 \\
Matrix-dominant failure & 1 & 0 & 0 & 0 & 0 & 1 & 1 & 1 & 0 \\
Delamination & 1 & 1 & 0 & 1 & 0 & 0 & 1 & 0 & 0 \\
Shear nonlinearity & 1 & 1 & 1 & 0 & 1 & 1 & 0 & 1 & 1 \\
\hline
\end{tabular}

When a failure criterion is reached, the stresses in the specific directions will drop to simulate the effect of damages. The relevant elastic constants of the composites at material integration points reduce to very small values based on the prescribed degradation rules. The elements with intact materials adjacent to the damaged materials carry additional loads applied to the structures and lead to stress redistribution. The material degradation rules of composite materials used in this study is shown in Table 2 . The effect of different material degradation rules on the failure prediction can be found in [16].

In addition to the material nonlinearity due to failure, the nonlinear in-plane shear stress-strain relation that is pertinent to unidirectional fiber composites is also incorporated into the material model. The idea is to examine the potential effects of shear nonlinearity on failure modes of the box beam. This is a concern when the box beam is loaded in the edgewise direction with unidirectional laminates in the spar caps under shear force. As proposed in [17], the nonlinear shear stress-strain relation of the unidirectional fiber composites is described as:

$\gamma_{12}=G_{12}^{-1} \sigma_{12}+\alpha \sigma_{12}^{3}$

where $\sigma_{12}$ and $\gamma_{12}$ are shear stress and shear strain, respectively. $G_{12}$ is the initial in-plane shear modulus of the ply. The nonlinear relation is characterized by the factor $\alpha$. Eq. (7) can be rewritten considering the nonlinear shear variable $d$ :

$\sigma_{12}=(1-d) G_{12} \gamma_{12}$

where

$d=\frac{3 \alpha G_{12} \sigma_{12}^{2}-2 \alpha \sigma_{12}^{3} / \gamma_{12}}{1+3 \alpha G_{12} \sigma_{12}^{2}}$

In this study, the in-plane shear stress versus strain test data are not available for the unidirectional composite material used in the specimen. In order to estimate the factor $\alpha$, the test data from [18], which reports shear properties of a unidirectional composite material that is similar to that used in this study, are used for curve fitting as shown in Figure 4. In this study, $\alpha=1.01 \times 10^{-7} \mathrm{MPa}^{-3}$ and $G_{12}=5.4$ $\mathrm{GPa}$ are found to be adequate to represent nonlinear in-plane shear response of unidirectional composites up to $1.7 \%$ shear strain, which covers the expected strain range experienced in the spar caps when the box beam is loaded in the edgewise direction.

Figure 4. Nonlinear in-plane shear response of the UD composites

\subsubsection{Foam core material}

It is known that PVC foam materials are typically anisotropic because of the manufacturing process [19]. The anisotropy is dependent on the density of the material. As observed in [20], the PVC foam Divinycell H250 with a nominal density of $250 \mathrm{~kg} / \mathrm{m}^{3}$ is strongly anisotropic, while the lower density PVC foams, Divinycell $\mathrm{H} 100$ with a nominal density of $100 \mathrm{~kg} / \mathrm{m}^{3}$, show nearly isotropic behavior. In this study, the PVC foams are assumed to be isotropic as they have a low nominal density of $50 \mathrm{~kg} / \mathrm{m}^{3}$. In order to predict the failure of foam materials, a crushable foam model is used as the crushing has been identified as a major failure mode observed in the test. The crushable foam model is based on a phenomenological constitutive relation. In addition to the isotropic elastic material properties, the 
model requires the definition of plasticity and the hardening rule after the material yields.

To define the crushable foam plasticity with volumetric hardening, it is necessary to know the ratio $k$ of the initial yield stress in uniaxial compression to the initial yield stress in hydrostatic compression and the ratio $k_{\mathrm{t}}$ of yield stress in hydrostatic tension to the initial yield stress in hydrostatic compression. Because two hydrostatic tests are difficult to conduct, experimental results from [21] are used to estimate two stress ratios. In the work [21], the PVC foam H100 is tested under uniaxial and hydrostatic loading, the stress ratios $k$ and $k_{\mathrm{t}}$ are approximately 0.91 and 2.2 , respectively. It is assumed that the foam materials used in this study have the same stress ratios as the H100 foams. Elastic and strength properties of the PVC foam materials used in the FE model are summarized in Table 3.

Table 3. Elastic and strength properties of PVC foam core materials used in the FE model.

\begin{tabular}{cccccc}
\hline \multicolumn{2}{c}{ Elastic properties parameters } & & \multicolumn{3}{c}{ Yield strength parameters } \\
\cline { 1 - 2 } \cline { 5 - 6 } $\mathrm{E}(\mathrm{MPa})$ & $\mu(-)$ & & $\sigma_{\mathrm{c}}{ }^{0}(\mathrm{MPa})$ & $k(-)$ & $k_{\mathrm{t}}(-)$ \\
35 & 0.3 & & 0.5 & 0.91 & 2.2 \\
\hline
\end{tabular}

To define the hardening rule, the relation between the yield stress in uniaxial compression and the corresponding plastic strain needs to be tabulated in the material model. Experimental results from uniaxial compression tests of the PVC foam are used to create these data and they are shown in Figure 5.

Figure 5. Uniaxial compressive response of the PVC foam

\subsubsection{Epoxy-based adhesive material}

Adhesive failure can be modeled using a few different methods in Abaqus [12]. Surface-based cohesive behavior is primarily used to model a bonded interface with a negligible thickness. If the interface adhesive layer has a finite thickness and material properties of the adhesive are known, cohesive elements are used to define the constitutive response of the adhesive material. In this study, cohesive elements are used to model the adhesive layer considering its design thickness of $3 \mathrm{~mm}$. In cohesive elements, three in-plane strains, i.e., two direct membrane strains and the in-plane membrane shear strain are assumed to be zero, and only three through-thickness strains are computed based on the element kinematics. The elastic behavior of cohesive elements can be written as a traction-separation relation and this study assumes uncoupled behavior between the normal and shear components.

$\left\{\begin{array}{l}\sigma_{n} \\ \sigma_{s} \\ \sigma_{t}\end{array}\right\}=\left[\begin{array}{lll}K_{n n} & & \\ & K_{s s} & \\ & & K_{t t}\end{array}\right]\left\{\begin{array}{l}\varepsilon_{n} \\ \varepsilon_{s} \\ \varepsilon_{t}\end{array}\right\}$

where the subscripts $n, s, t$ designate the normal, the first and the second shear components in the through-thickness direction, respectively. $\sigma_{i}(i=n, s, t)$ and $\varepsilon_{i}(i=n, s, t)$ are the nominal stress and the nominal strain, respectively. $K_{i i}(i=n, s, t)$ is the corresponding stiffness of the adhesive layer. The initial stiffness is calculated by $K_{n n}^{0}=a E_{a d} / t$ and the value of $a$ is proposed to be 50 according to [22]; $E_{a d}$ is the elastic modulus of the adhesive material which is $3.5 \mathrm{GPa} . t$ is the thickness of the adhesive layer and the design value of $3 \mathrm{~mm}$ is used. $K_{s s}^{0}$ and $K_{t t}^{0}$ are assumed to be the same as $K_{n n}^{0}$ due to the isotropy of the adhesive material.

The cohesive element model assumes that failure initiates when the following quadratic stress-based failure criterion is satisfied,

$f_{D E}=\left(\frac{\left\langle\sigma_{n}\right\rangle}{\sigma_{n}^{0}}\right)^{2}+\left(\frac{\sigma_{s}}{\sigma_{s}^{0}}\right)^{2}+\left(\frac{\sigma_{t}}{\sigma_{t}^{0}}\right)^{2} \geq 1,\left\langle\sigma_{n}\right\rangle=\left\{\begin{array}{cc}\sigma_{n} & \sigma_{n}>0 \\ 0 & \sigma_{n} \leq 0\end{array}\right.$

where $\sigma_{i}^{0}$ is the peak value of the nominal stress and $\sigma_{i} / \sigma_{i}^{0}(i=n, s, t)$ is the stress ratio. The damage evolution law describes the rate at which the material stiffness is degraded once the failure criterion is reached. In this study, the process of damage evolution is defined based on the energy dissipated during fracture per unit of newly created fracture surface area, or the strain energy release rate. In the general case involving mode I, II and III, a crack will grow if the fracture criterion defined by Eq. (12) is satisfied. 
$f_{F R}=\frac{G_{T}}{G_{T}^{C}} \geq 1$

where $G_{T}=G_{I}+G_{I I}+G_{I I I}$ is the total available strain energy release rate. $G_{I}$, $G_{I I}$ and $G_{I I I}$ are the energy per unit crack surface area available for mode I, II and III cracks, respectively. $G_{T}^{C}$ is the total critical strain energy release rate. A few formulae can be used to compute $G_{T}^{C}$. The Benzeggagh-Kenane criterion [23] as shown in Eq. (13) is originally developed for the mixed mode I and II.

$G_{T}^{C}=G_{I}^{C}+\left(G_{I I}^{C}-G_{I}^{C}\right)\left(\frac{G_{I I}}{G_{I}+G_{I I}}\right)^{\eta}$

where $G_{I}^{C}, G_{I I}{ }^{C}$ and $G_{I I I}$ are the critical strain energy rates for the corresponding fracture modes. $\eta$ is a material constant. The Reeder criterion [24] extends the Benzeggagh-Kenane criterion to 3D to include mode III and it is described as:

$G_{T}^{C}=G_{I}^{C}+\left(G_{I I}^{C}-G_{I}^{C}\right)\left(\frac{G_{I I}+G_{I I I}}{G_{I}+G_{I I}+G_{I I I}}\right)^{\eta}+\left(G_{I I I}^{C}-G_{I I}^{C}\right)\left(\frac{G_{I I I}}{G_{I I}+G_{I I I}}\right)\left(\frac{G_{I I}+G_{I I I}}{G_{I}+G_{I I}+G_{I I I}}\right)^{\eta}$

When assuming the response to mode III is similar to mode II since they are both shear types of loading, i.e., $G_{I I}{ }^{C}=G_{I I I}{ }^{C}$, the Reeder criterion reduces to the Benzeggagh-Kenane criterion in the 3D formulation which has been implemented in Abaqus [12]:

$G_{T}^{C}=G_{I}^{C}+\left(G_{I I}^{C}-G_{I}^{C}\right)\left(\frac{G_{I I}+G_{I I I}}{G_{I}+G_{I I}+G_{I I I}}\right)^{\eta}$

The material constant $\eta=1.75$ is used in this study and other material parameters are summarized in Table 4 .

Table 4. Material parameters used to model adhesive materials

\begin{tabular}{cccc}
\hline Stress direction & $K_{i i}^{0}\left(\mathrm{kN} / \mathrm{m}^{3} \times 10^{9}\right)$ & $t_{i}^{0}(\mathrm{MPa})$ & $G_{i}^{C}\left(\mathrm{~kJ} / \mathrm{m}^{2}\right)$ \\
\hline Normal $(n)$ & 58.3 & 42.0 & 1.2 \\
First shear $(s)$ & 58.3 & 40.0 & 6.0 \\
Second shear $(t)$ & 58.3 & 40.0 & 6.0 \\
\hline
\end{tabular}

\section{Results and discussion}

Using the proposed modeling method, structural response of the box beams under flapwise and edgewise loading is analyzed. The applied load versus displacement response is predicted and it is compared to experimental results. Local strain response during the loading is examined to understand the buckling behavior of box beams. The predicted failure modes and their characteristics are simulated and compared to those observed in the test. The progress of different damages in the box beams is studied to understand failure behavior associated with multiple structural nonlinearities.

\subsection{Applied load versus displacement response}

The predicted applied load versus displacement curves of the box beams under flapwise and edgewise loading are compared with the experimental results as shown in Figure 6. In each loading case, the displacements of both right $(R)$ and left $(L)$ side of the middle span were measured in the experiments. In FEA, only one prediction is plotted as both sides deform the same in the model. It can be seen that FE models predict the global structural response of box beams reasonably well. The ultimate loads are well predicted in both cases with a few percent deviations from the experimental results. In terms of the overall stiffness, the box beam under flapwise loading is around $11 \%$ overestimated by the model. For the box beam under edgewise loading, the initial nonlinear response is not predicted while the tangential stiffness is predicted with a slight underestimation. The experimental results and FEA predictions are summarized in Table 5.

Figure 6. Comparison of numerical and experimental load-displacement response of box beams 
Table 5. Comparison of linear tangential stiffness and ultimate load of box beams (Experimental data from [1])

\begin{tabular}{|c|c|c|c|c|c|c|c|}
\hline \multirow[t]{2}{*}{ Specimens } & \multicolumn{3}{|c|}{ Linear tangential stiffness $(\mathrm{kN} / \mathrm{mm})$} & \multirow{2}{*}{$\begin{array}{c}\text { Difference (\%) } \\
(F E A-E x p .) / E x p .\end{array}$} & \multicolumn{2}{|c|}{ Ultimate load $(\mathrm{kN})$} & \multirow{2}{*}{$\begin{array}{c}\text { Difference (\%) } \\
(F E A-E x p .) / E x p .\end{array}$} \\
\hline & Exp._R & Exp._L & $F E A$ & & Exp. & $F E A$ & \\
\hline CB_F2 & 9.06 & 10.20 & 10.72 & 11.32 & 43.30 & 44.16 & 1.99 \\
\hline CB_E2 & 7.42 & 6.76 & 6.94 & -2.12 & 87.60 & 80.96 & \\
\hline
\end{tabular}

It is worth noting that the post-peak response of both box beams is captured to a large extent by the models. For the flapwise loading case, both displacement and applied loads drop progressively, resulting in a reverse load versus displacement curve as observed in the experiment. When the applied load drops to approximately $23 \mathrm{kN}$, the simulation terminates due to convergence difficulty likely caused by significant material damages. The last part of the experimental curve, which shows a 'snap-through' pattern with an increase of displacement, is not captured by the model. For the edgewise loading case, the applied load drops drastically once the ultimate load of the box beam is reached. This simulation result agrees with experimental observation very well.

\subsection{Applied load versus strain response}

The predicted strains at a few typical locations are compared with experimental results as shown in Figure 7. In the figure, only the results until the peak load are plotted to understand local structural response leading to the ultimate strength. For the flapwise loading case, i.e., CB_F2, the longitudinal strain at the bottom spar cap at the $0 \mathrm{~mm}$ cross section responds linearly to the applied load. Both longitudinal and transverse strain at the top spar cap at the $200 \mathrm{~mm}$ cross section exhibit nonlinear behavior with both strain curves leaning towards a positive, or tensile, regime. This finding indicates the spar cap at this location is bulging out during the loading. The FE results predict this phenomenon reasonably.

Figure 7. Comparison of numerical and experimental load-strain response of box beams

For the edgewise loading case, i.e., CB_E2, the shear webs behave linearly with the increase of applied loads, which is captured well by the numerical model. While the spar caps show nonlinear behavior from the beginning of the loading evident from transverse strains at the $0 \mathrm{~mm}$ cross section. Although a large quantitative discrepancy exists between the experiment and the simulation, the model is able to show the general trend of local structural response that both spar caps of the box beams are bugling out during the loading.

\subsection{Failure prediction}

This section presents the predicted failures of two box beams with comparisons to experimental observations. For the box beam under flapwise loading, both the final failures and the intermediate failures leading to the final failure are presented. For the box beam under edgewise loading, only the final failures are presented as the development of failures in this box beam is less significant compared to the counterpart beam under flapwise loading before the peak load. A summary of the failure process of both box beams is presented at the end of this section.

\subsubsection{Failure of the box beam under flapwise loading}

\section{- Composite failure}

The final failures of the box beam are predicted and they are shown in Figure 8 together with experimental observations. The failures occur in the skin laminates of two sandwich shear webs underneath the loading plate. Three failure modes of composite materials are predicted. The fiber-dominant failure mainly occurs in the inside skin of the shear webs which agrees well with the experiment. The matrix-dominant failure is significant in both the inside and the outside skins. The delamination shows a similar feature to the matrixdominant failure and it spreads in the skin laminates on both sides of the shear webs. It is worth noting that in addition to the failure 
modes, the features, or characteristics, of failures that have been observed in the experiment are also captured reasonably. For example, the curved pattern of the laminate crack and the coexistence of the matrix-dominant failure and delamination.

Figure 8. The predicted final failure of skin composites in sandwich shear webs of CB_F2

Using this numerical model, the distribution of transverse strains at the final failure is examined as shown in Figure 9. It can be seen that a correlation exists between composite failure and transverse strains. In the shear web, the skin composites close to the loading plates are subject to transverse compression as shown in blue. A transverse tensile region is located underneath this compressive region due to the bugling out deformation. Another transverse compressive region exists as a curved band, suggesting the composite failure at this location is contributed by transverse compression. The simulation results agree with the previous findings [1] and provide evidence on the nature of composite failures at different locations.

Figure 9. Correlation between failure observations and transverse strains in the shear web

\section{- Foam core failure}

The failure process of foam cores in the shear webs at the middle cross section of the box beam is presented in Figure 10. The yielding of the foam core starts at $95 \%$ of the peak load due to the local out-of-plane deformation of the shear webs adjacent to the adhesive joint. The yielding region propagates with the foam core crushing due to increased local deformation. The failure of skin composites can be also seen in this figure, suggesting the inside skin has a more significant fiber-dominant failure than the outside one, which agrees with the previous finding. The final failure of the foam core material exhibits a curved pattern underneath the loading plate and it appears to be in good agreement with the final failure pattern observed in the experiment as shown in Figure 8.

Figure 10. The predicted PVC foam failure in the shear webs

\section{- Adhesive failure}

The predict failure process of adhesive material around the middle section of the box beam is shown in Figure 11. It shows the failure starts at the inside edge of the bondline close to the loading plate at $95 \%$ of the peak load. This is probably due to significant stresses generated by the transverse deformation of the top spar cap and the out-of-plane deformation of the shear web adjacent to the adhesive joint. The region of failure becomes larger at the peak load. A new failure location appears at the outside edge of the bondline in the post-peak regime and it propagates until the final failure of the specimen.

Figure 11. Predicted failure progress of adhesives in the box beam

A comparison between the predicted final adhesive failure and experimental observations is shown in Figure 12. It can be seen that two major locations of failure are predicted in good agreement with experimental observations. The first location is just underneath the loading plate and the adhesive cracks exhibit vertical cracks in the test. The second location is from approximately 100 to $160 \mathrm{~mm}$ away from the middle cross section of the box beam. The failure of adhesive shows oblique cracks and debonding.

Figure 12. Comparison between the predicted and the observed final adhesive failure 


\subsubsection{Failure of the box beam under edgewise loading}

In the box beam under edgewise loading, the only failures observed in the test are composite failure and adhesive failure. Figure 13 shows the predicted failures with comparison with experimental observations after the test. It can be seen that both fiber-dominant and matrix-dominant failure occur in the spar caps in the region underneath the loading plate. Moreover, significant delamination is predicted to occur in the spar caps as observed in the specimen. There are two locations of adhesive failure based on the simulation. The first location is right underneath the loading plate and the second location is at the inside edge of the bondline. In the post-test specimen, it is difficult to distinguish these predicted locations due to significant adhesive failure, nevertheless, the region of adhesive failure is found to be in reasonable agreement with the one found in the experiment.

Figure 13. The final failure of the box beam under edgewise loading

\subsubsection{Summary of the failure process}

Based on the numerical simulations presented in this study and the previous experimental findings from [1], the failure process of the box beams under two different loading conditions can be summarized as shown in Figure 14.

Figure 14. The predicted failure process of two box beams under different loading directions

For the box beam loaded in the flapwise direction, the transverse deformation of the top spar cap and the accompanying local out-ofplane deformation of the shear webs occur at the early stage when the global structural response is still linear. The foam core in the shear webs starts to yield due to the local deformation and continues to experience crushing failure. Adhesive joints start to show failure locally. Delamination and the matrix-dominant failure occur in the skin laminates before the peak load of the box beam is reached. The fiberdominant failure starts after the peak load and all failures propagate in the post-peak regime.

For the box beam loaded in the edgewise direction, two spar caps start to bulge out followed by local delamination underneath the loading plate. The matrix-dominant failure and the fiber-dominant failure occur sequentially in the same local region before the peak load of the box beam is reached. The adhesive failure starts right after the peak load and it propagates rapidly together with composite failures, resulting in a drastic drop of the load-carrying capacity of the box beam as observed in the experiment.

\section{Concluding remarks}

In this study, a comprehensive and general FE modeling approach is developed to predict multiple failure modes of composite box beams used in wind turbine blades. Three types of structural nonlinearities originated from geometry, materials and contact have been taken into account. The failures of composite materials, foam cores and adhesives are incorporated in the model in a three-dimensional stress/strain state to predict failure modes and their characteristics. Extensive comparisons between numerical predictions and experimental results show that the structural response of composite box beams is predicted reasonably using the proposed modeling approach. Different failure modes and their characteristic features are captured in good agreement with experimental observations. Although the modeling approach presented in this study is developed for predicting multiple failures of composite box beams, it is of generic nature and could be applied to the entire wind turbine blades if the similar failure modes are of interest. This FE modeling approach has a promising potential to facilitate the damage-tolerant design of composite wind turbine blades through reasonable failure prediction at a large structural scale. The future works include comprehensive parametric studies of material damage models and the effect of different blade designs on the change of dominating failure modes especially when rotor blades scale up. 


\section{Acknowledgements}

This study was partially supported by the National Natural Science Foundation of China (grant number 51405468). We would like to thank anonymous reviewers for the suggestion and comments to this work.

\section{Appendix}

A linear eigenvalue buckling analysis is performed to generate the assumed geometric imperfection of the box beam. The geometric imperfection is used to initiate the desired deformation that was observed in the test. Because the linear buckling analysis does not consider any structural nonlinearities, the geometric model of the box beam is modified to exclude contact surfaces as shown in Figure A1. Element nodes are shared at the interfaces between the loading plates except that between the top spar cap and the rubber pad, allowing them to separate from each other. The peak load is applied and the buckling mode with two shear webs bugling out in a symmetric manner is downscaled to generate the geometric imperfection in the FE model for the nonlinear FE analysis.

Figure A1. The FE model used in the linear buckling analysis

\section{Reference}

[1] Tang J, Chen X. Experimental investigation on ultimate strength and failure response of composite box beams used in wind turbine blades. Composite Structures 2018;198:19-34.

[2] Florian Sayer, Alexandros Antoniou, Arnoldus van Wingerde, Investigation of structural bond lines in wind turbine blades by subcomponent tests, International Journal of Adhesion and Adhesives, Volume 37, September 2012, Pages 129-135.

[3] Cole B, Miyase A, Yu TP, Lo KH, Wang SS. Failure modes and strength of composite box beam structures. Proceeding of the American Society for Composites $30^{\text {th }}$ Annual Technical Conference, 2015.

[4] Yu TP, Miyase A, Lo KH, Wang SS. Composite box-beam failure modes and strength: 3D modeling and analysis and comparison with experimental results. Proceeding of the American Society for Composites 31th Annual Technical Conference, 2016.

[5] Chen X, Zhao XL, Xu JZ. Revisiting the structural collapse of a $52.3 \mathrm{~m}$ composite wind turbine blade in a full-scale bending test. Wind Energy, 2017, 20 (6):1111-1127.

[6] Chen X, Qin ZW, Yang K, Zhao XL, Xu JZ. Numerical analysis and experimental investigation of wind turbine blades with innovative features: structural response and characteristics. Sci China Technol Sci 2015;58(1):1-8.

[7] Chen X. Experimental investigation on structural collapse of a large composite wind turbine blade under combined bending and torsion. Composite Structures, 2017;160:435-445.

[8] O. Al-Khudairi, H. Ghasemnejad, To improve failure resistance in joint design of composite wind turbine blade materials, Renewable Energy 2015, 81, 936-951.

[9] David W. Palmer, Lawrence C. Bank, T. Russell Gentry, Progressive tearing failure of pultruded composite box beams: experiment and simulation, Composites Science and Technology, Volume 58, Issue 8, August 1998, Pages 1353-1359.

[10] Jensen FM, Puri AS, Dear JP, Branner K, Morris A, Investigating the impact of non-linear geometrical effects on wind turbine blades - Part1: Current status of design and test methods and future challenges in design optimization, Wind Energy. 2011: 14: 239-254.

[11] Puri AS, Researching the non-geometrical effects casued by static flap-wise loading of a wind turbine blade, PhD thesis, Imperial College London. 2010.

[12] Dassault Systemes Simulia Corp. ABAQUS/Standard User's Manual, 2016.

[13] Tsai SW, Wu EM. A general theory of strength for anisotropic materials. Journal of Composite Materials. 1971; 5:58-80.

[14] Hashin Z. Failure Criteria for Unidirectional Fiber Composites, Journal of Applied Mechanics, Volume 47, Issue 2, 329-334, 1980.

[15] Christensen RM. The Theory of Material Failure. Oxford University Press: Oxford, UK, 2013.

[16] Chen X, Zhao W, Zhao X, Xu J. Failure Test and Finite Element Simulation of a Large Wind Turbine Composite Blade under 
Static Loading. Energies 2014;7(4):2274-2297.

[17] Chang FK, Lessard LB. Damage Tolerance of Laminated Composites Containing an Open Hole and Subjected to Compressive Loadings: Part I-Analysis. Journal of Composite Materials 1991;25:2-43.

[18] Samborsky DD, Mandell JF, Agastra P. 3-D Static Elastic Constants and Strength Properties of a Glass/Epoxy Unidirectional Laminate. AIAA SDM Conference, Wind Energy Session, Boston; 2013.

[19] S.T. Taher, O.T. Thomsen, J.M. Dulieu-Barton, S. Zhang, Determination of mechanical properties of PVC foam using a modified Arcan fixture, Composites Part A: Applied Science and Manufacturing, Volume 43, Issue 10, October 2012, Pages 1698-1708.

[20] E.E Gdoutos, I.M Daniel, K.-A Wang, Failure of cellular foams under multiaxial loading, Composites Part A: Applied Science and Manufacturing, Volume 33, Issue 2, February 2002, Pages 163-176.

[21] V.S Deshpande, N.A Fleck, Multi-axial yield behaviour of polymer foams, Acta Materialia, 49(10),2001, 1859-1866.

[22] Turon A, Dávila CG, Camanho PP, Costa J. An engineering solution for mesh size effects in the simulation of delamination using cohesive zone models. Engineering Fracture Mechanics 2007;74(10):1665-1682.

[23] Benzeggagh ML, Kenane M. Measurement of mixed-mode delamination fracture toughness of unidirectional glass/epoxy composites with mixed-mode bending apparatus. Composites Science and Technology 1996;56(4):439-449.

[24] Reeder, J., S. Kyongchan, P. B. Chunchu, and D. R. Ambur, Postbuckling and Growth of Delaminations in Composite Plates Subjected to Axial Compression, 43rd AI AA/ASME/ASCE/AHS/ASC Structures, Structural Dynamics, and Materials Conference, Denver, Colorado, vol. 1746, p.10, 2002. 


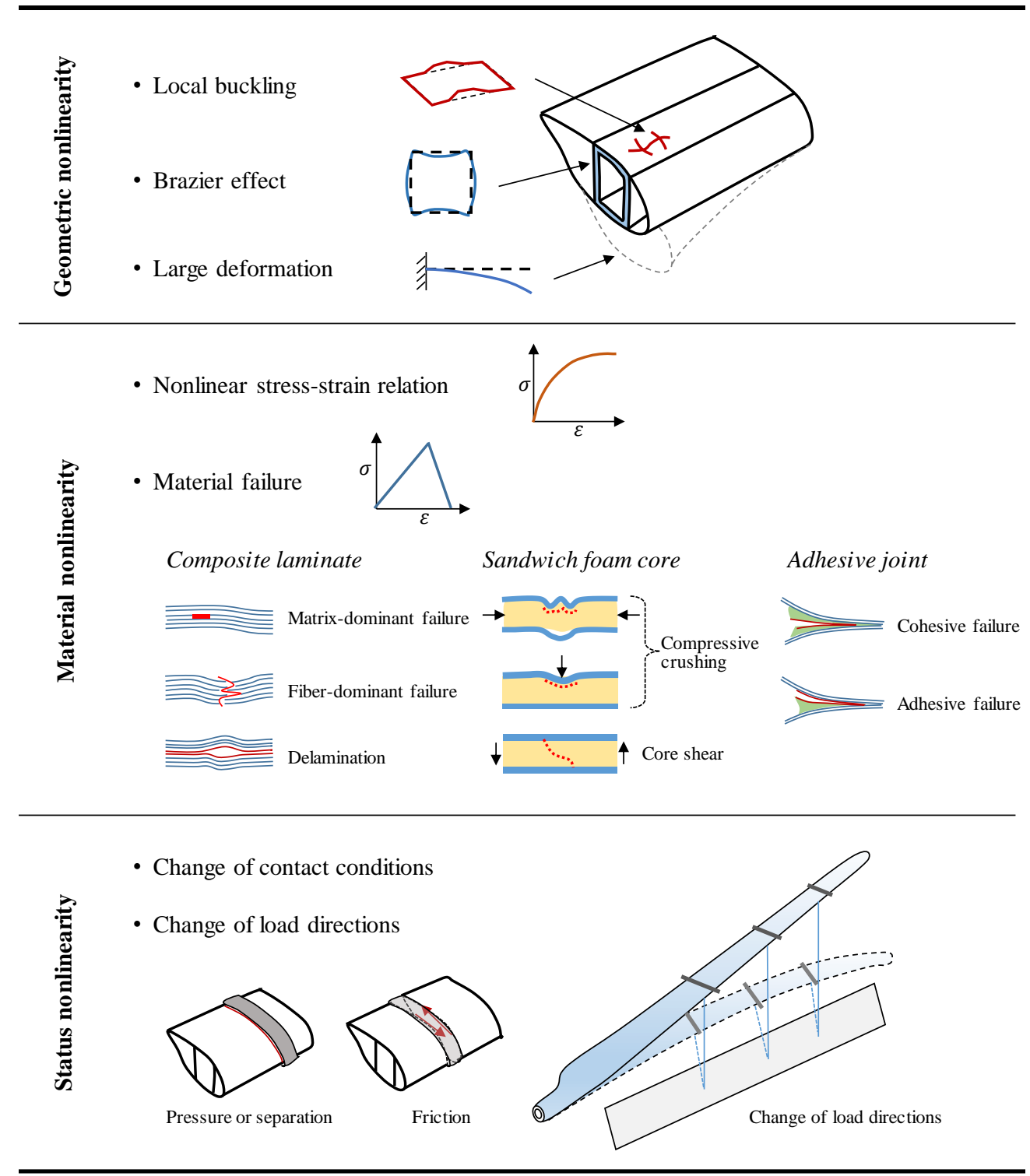

Figure 1. Examples of structural nonlinearities that might be experienced by composite wind turbine blades 

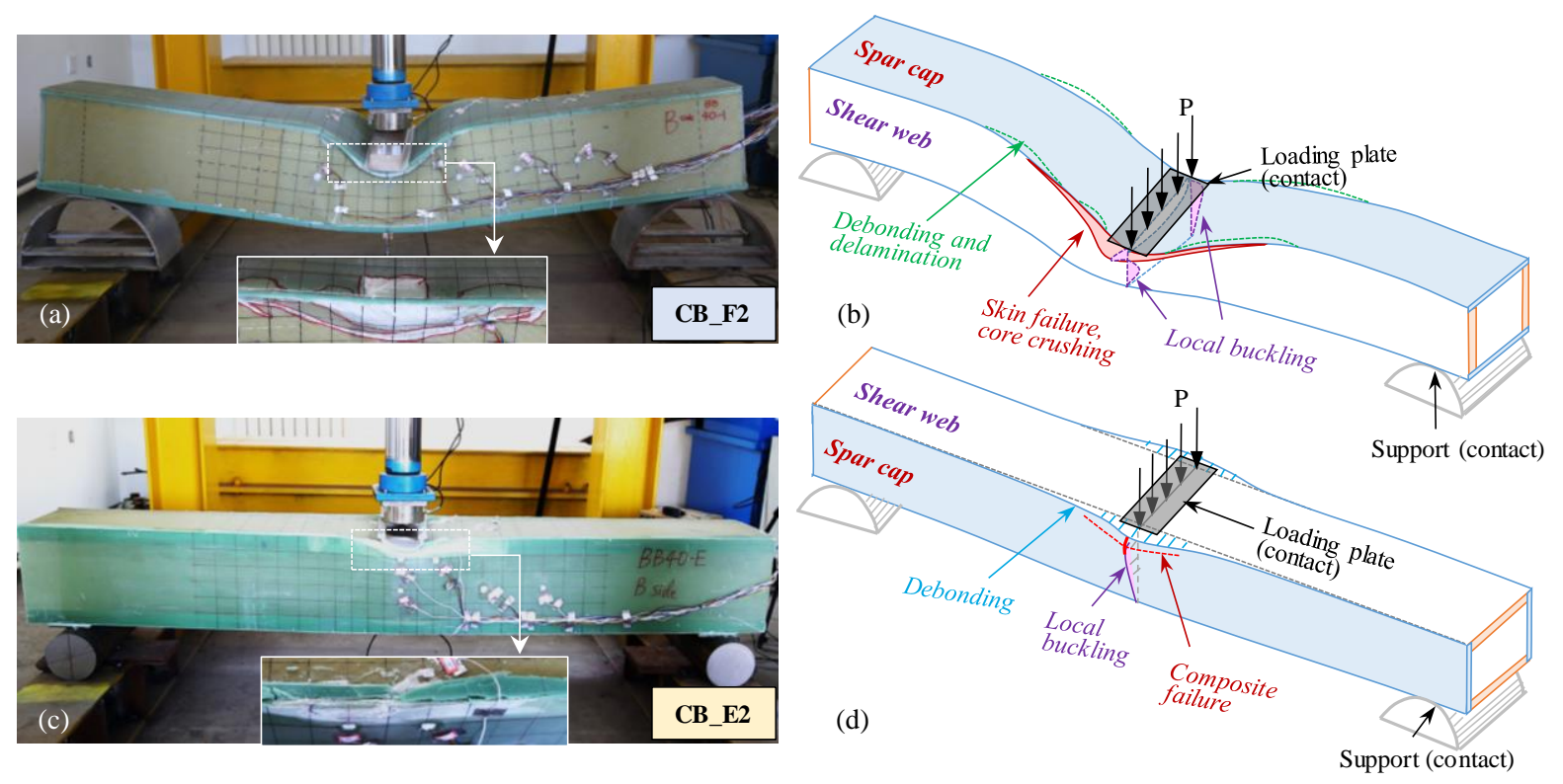

Figure 2. Experimental observations and illustration of failures in composite box beams (Experiment [1]) 


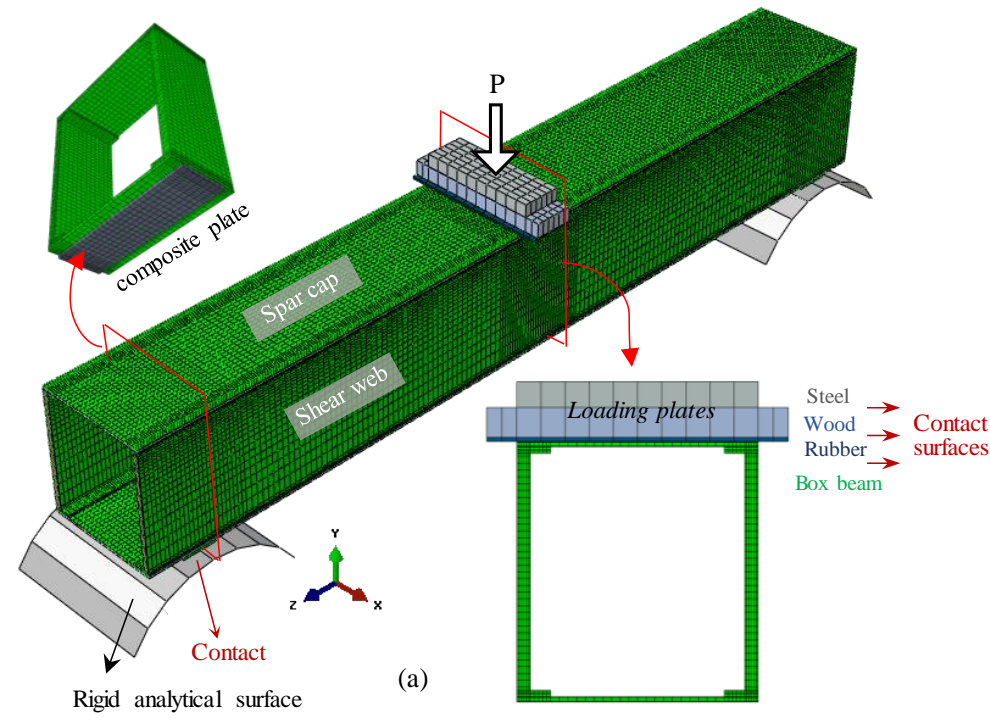

(b)

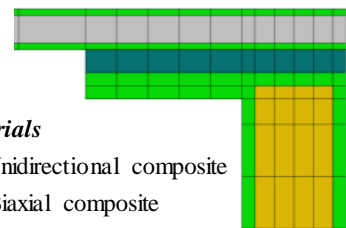

$\square$ Unidirectional composite

$\square$ Biaxial composite

$\square \quad$ PVC foam

$\square$ Epoxy-based adhesive

(c)

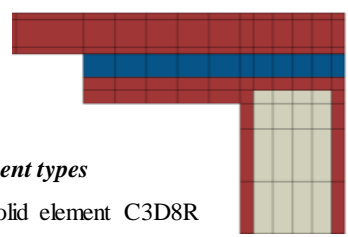

Solid element

$\square$ Solid element C3D8R

$\square$ Cohesive element COH3D8

Figure 3. Geometric model of the box beam under flapwise loading 


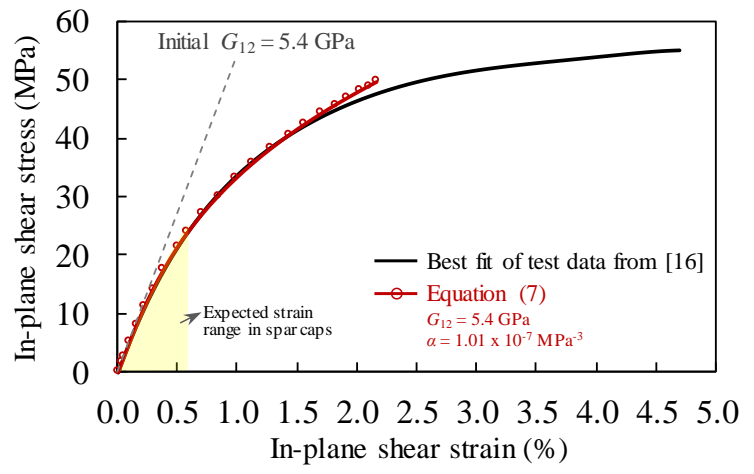

Figure 4. Nonlinear in-plane shear response of the UD composites 


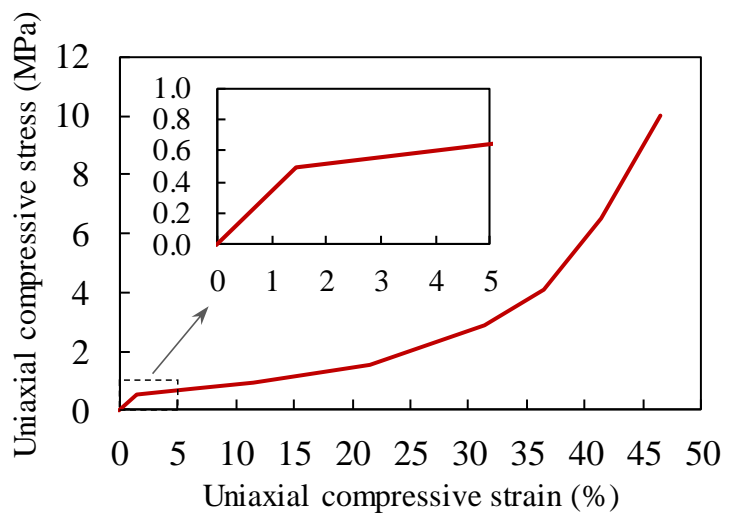

Figure 5. Uniaxial compressive response of the PVC foam 


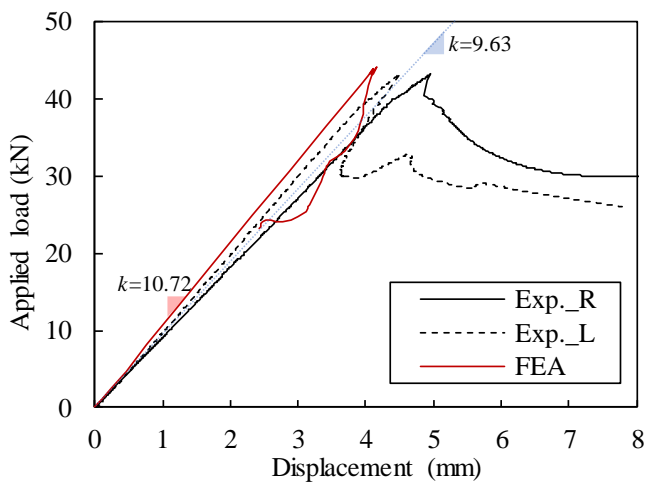

(a) CB_F2 under flapwsie loading

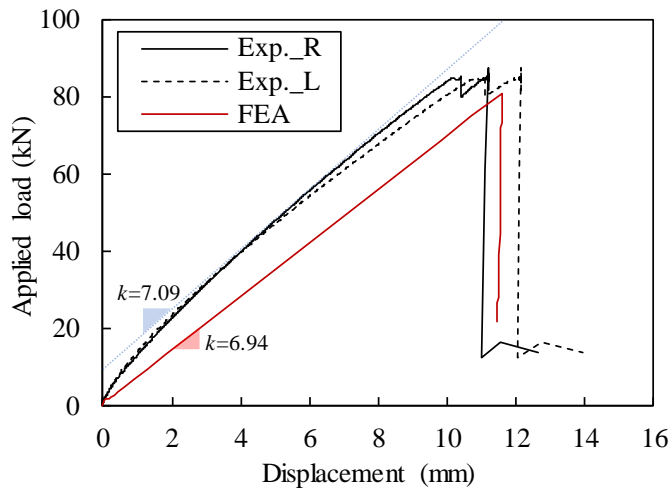

(b) CB_E2 under edgewsie loading

Figure 6. Comparison of numerical and experimental load-displacement response of box beams 

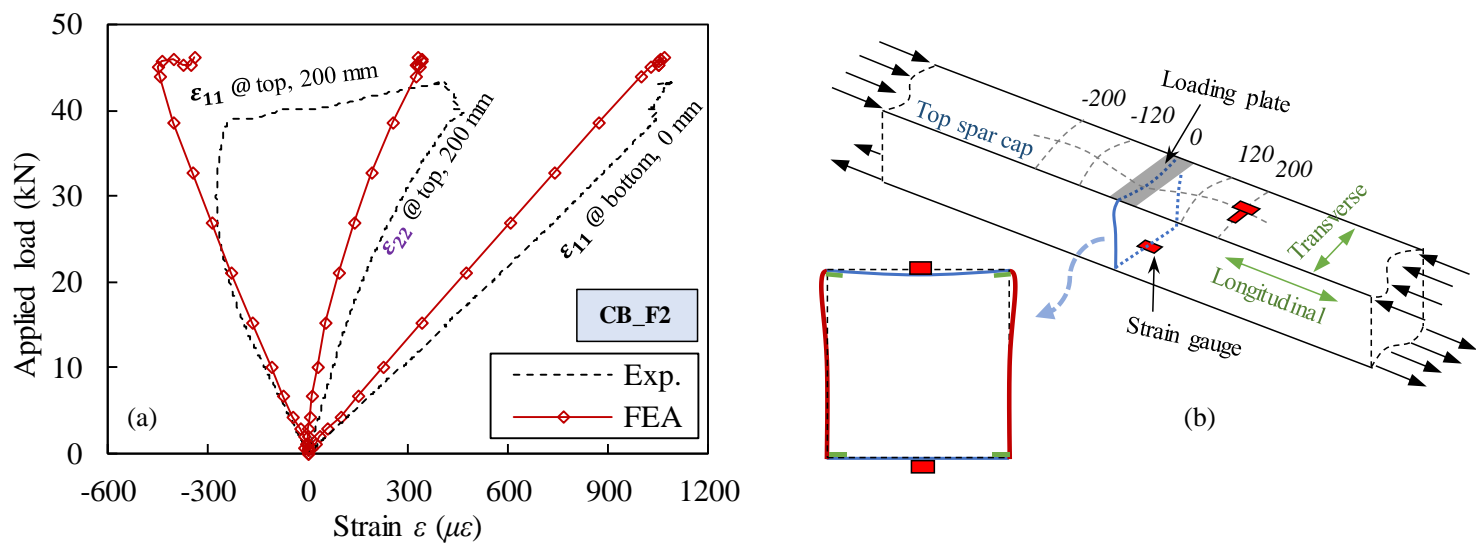

(b)
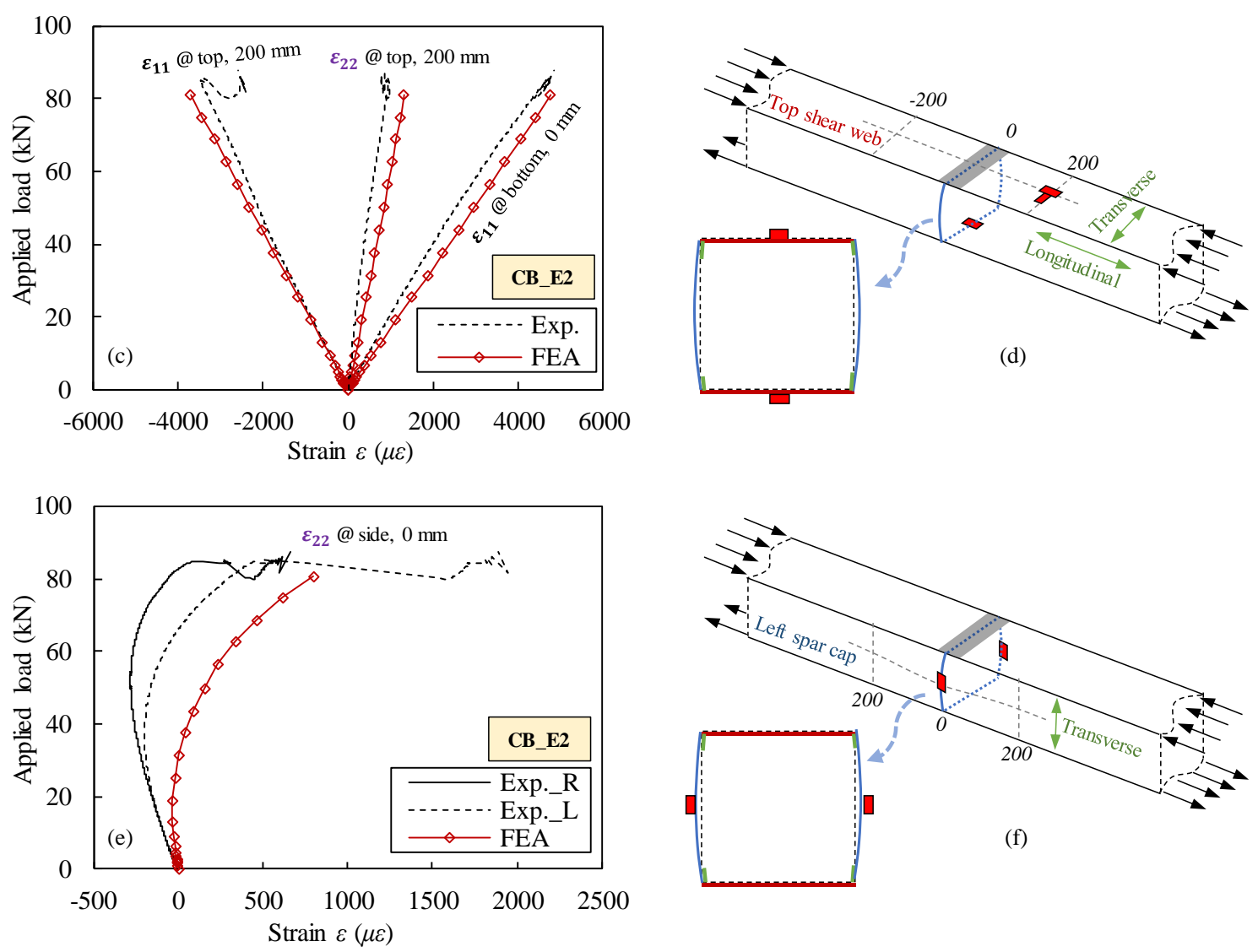

Figure 7. Comparison of numerical and experimental load-strain response of box beams 

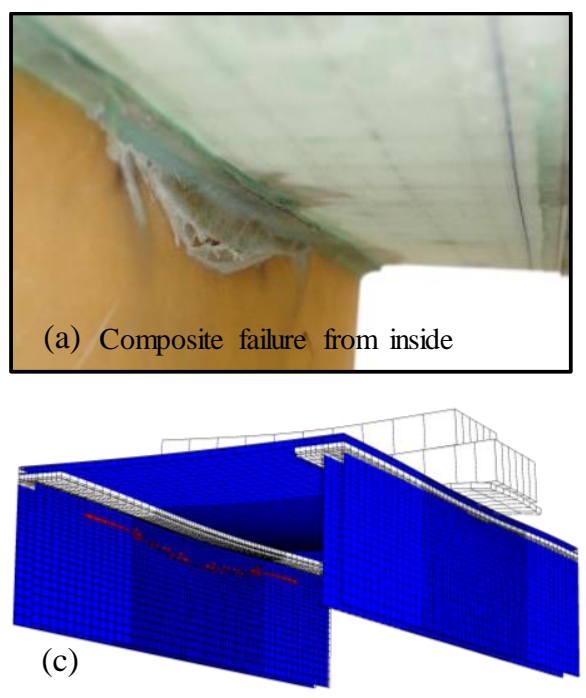

$\square$ Fiber-dominant failure
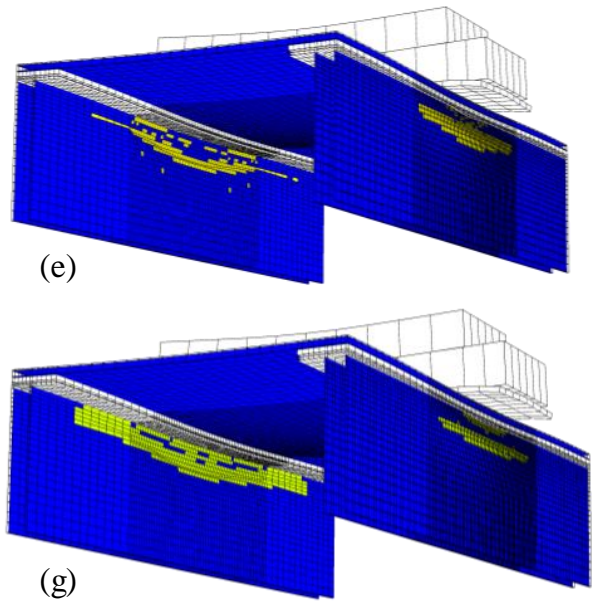
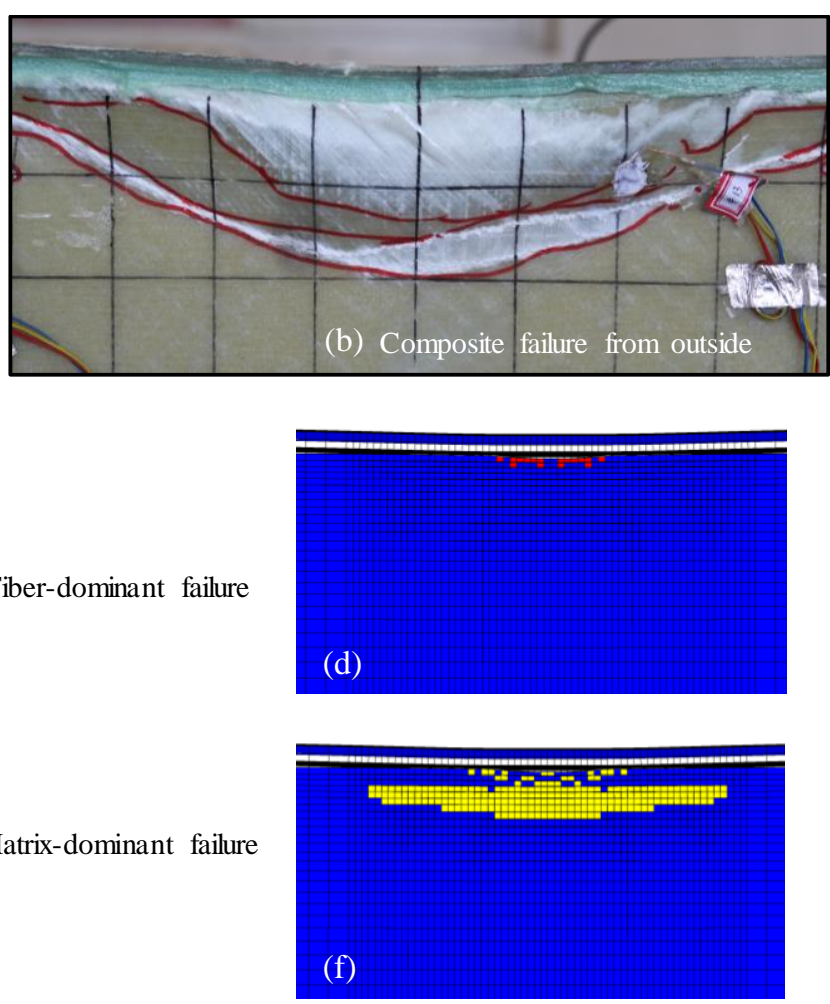

$\square$ Delamination

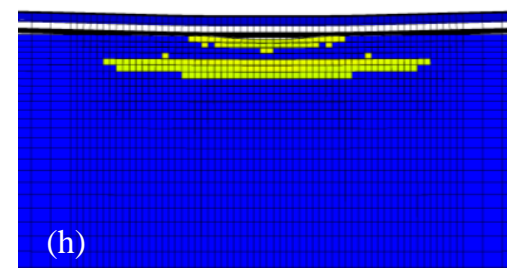

Figure 8. The predicted final failure of skin composites in sandwich shear webs of CB_F2 

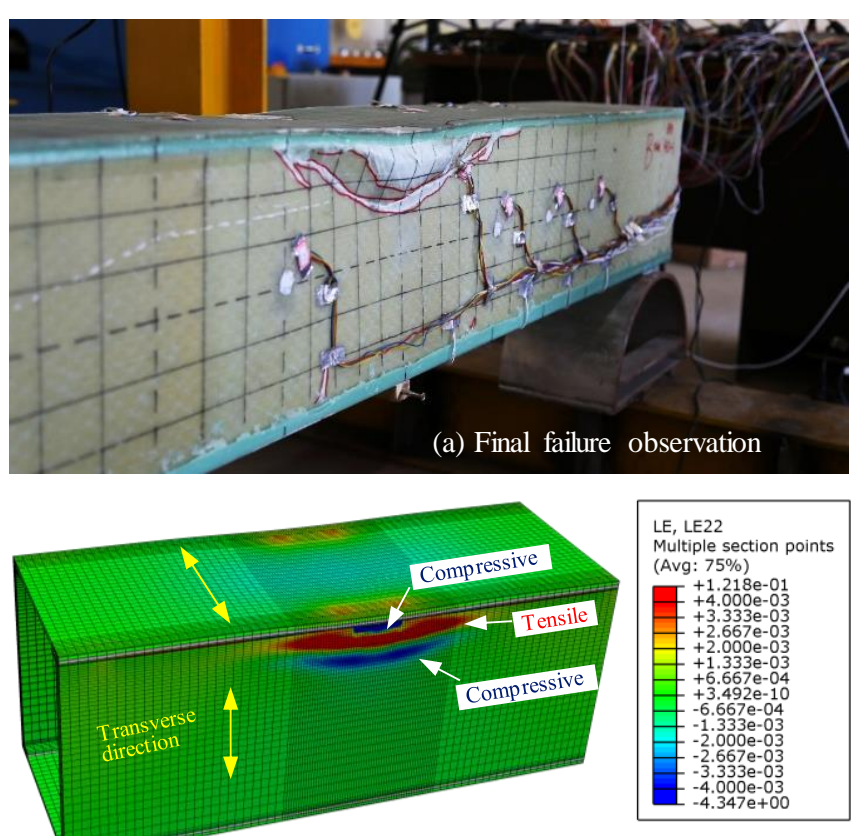

(b) Transverse strain distribution at final failure

Figure 9. Correlation between failure observations and transverse strains in the shear web 

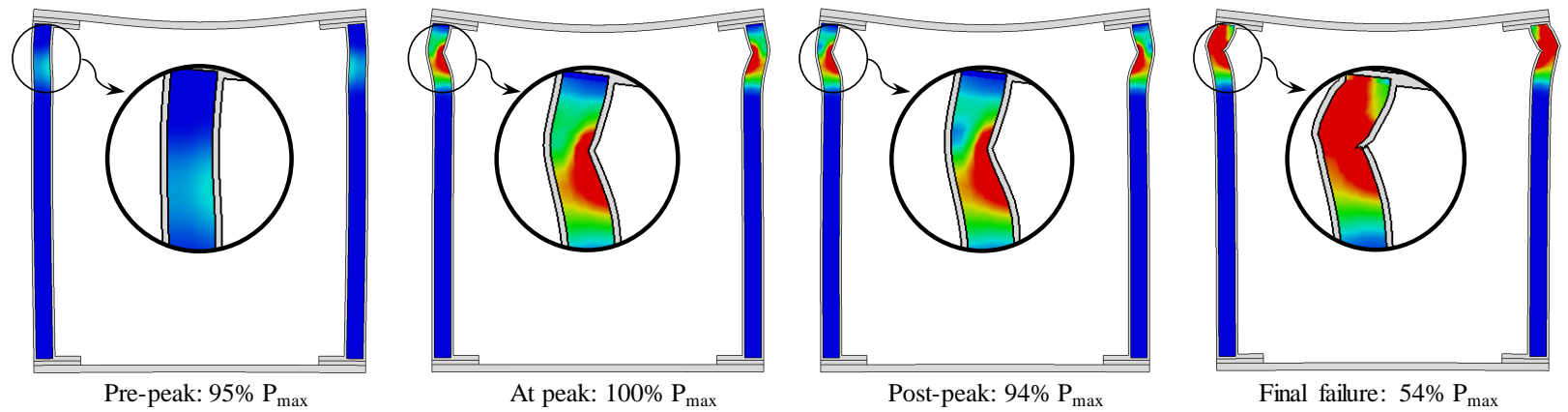

(a) The predicted failure progress at the middle cross section
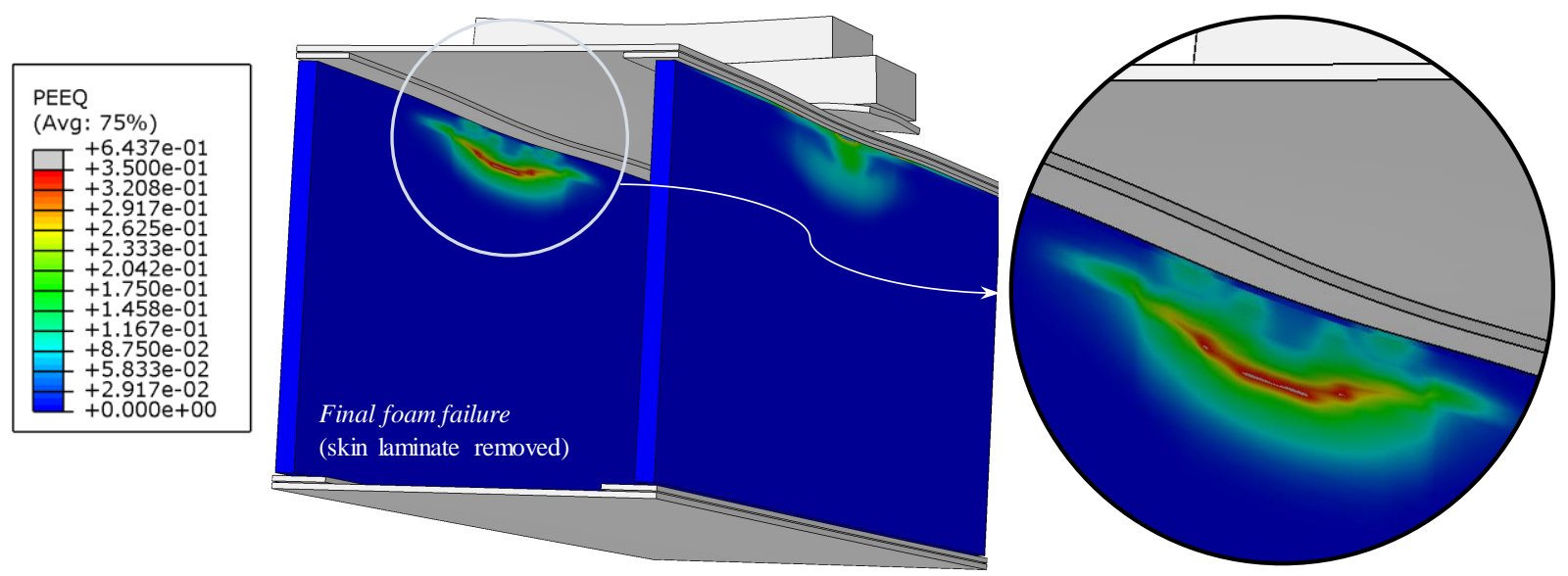

(b) The predicted final failure of the PVC foam

Figure 10. The predicted PVC foam failure in the shear webs 


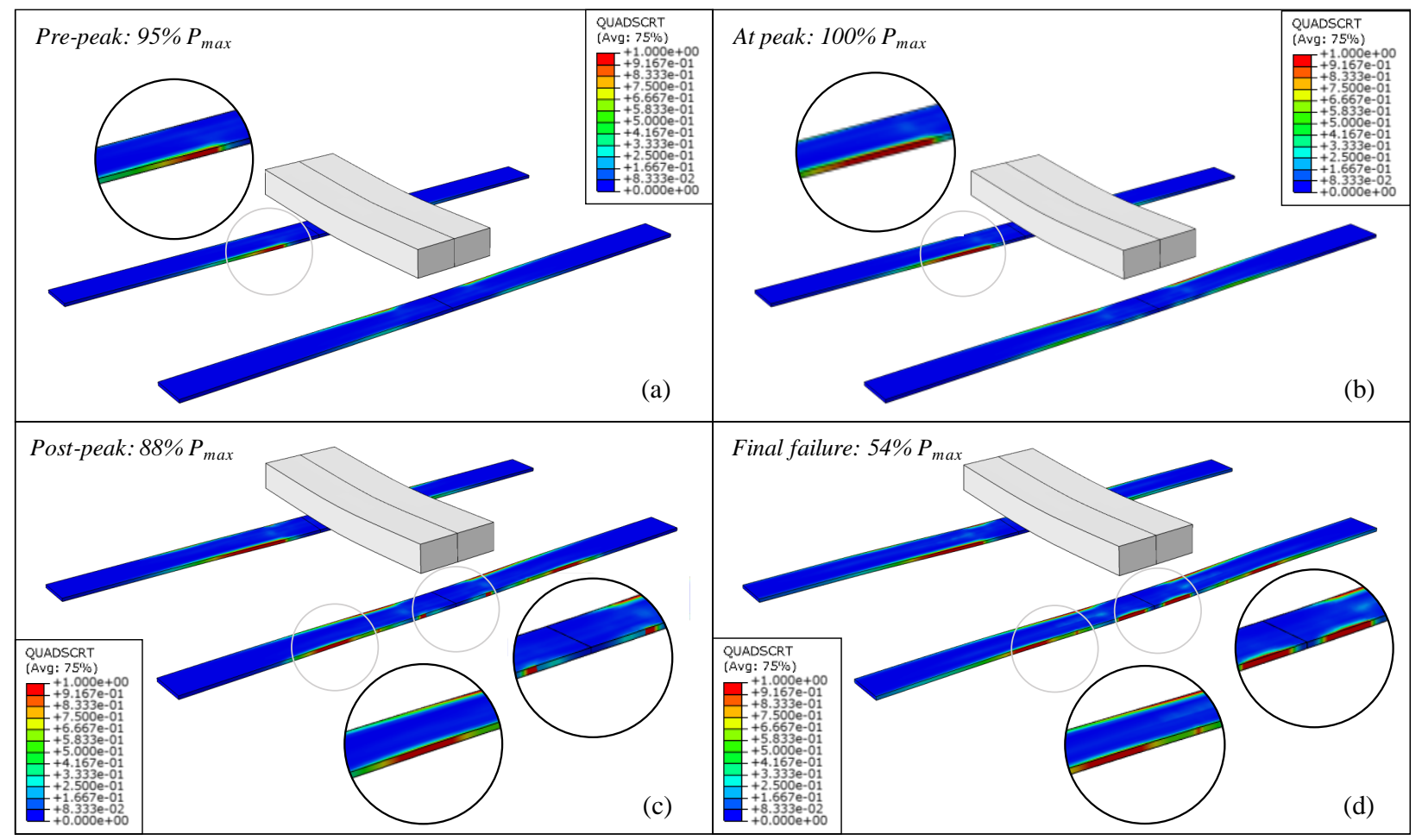

Figure 11. The predicted failure progress of adhesives in the box beam 


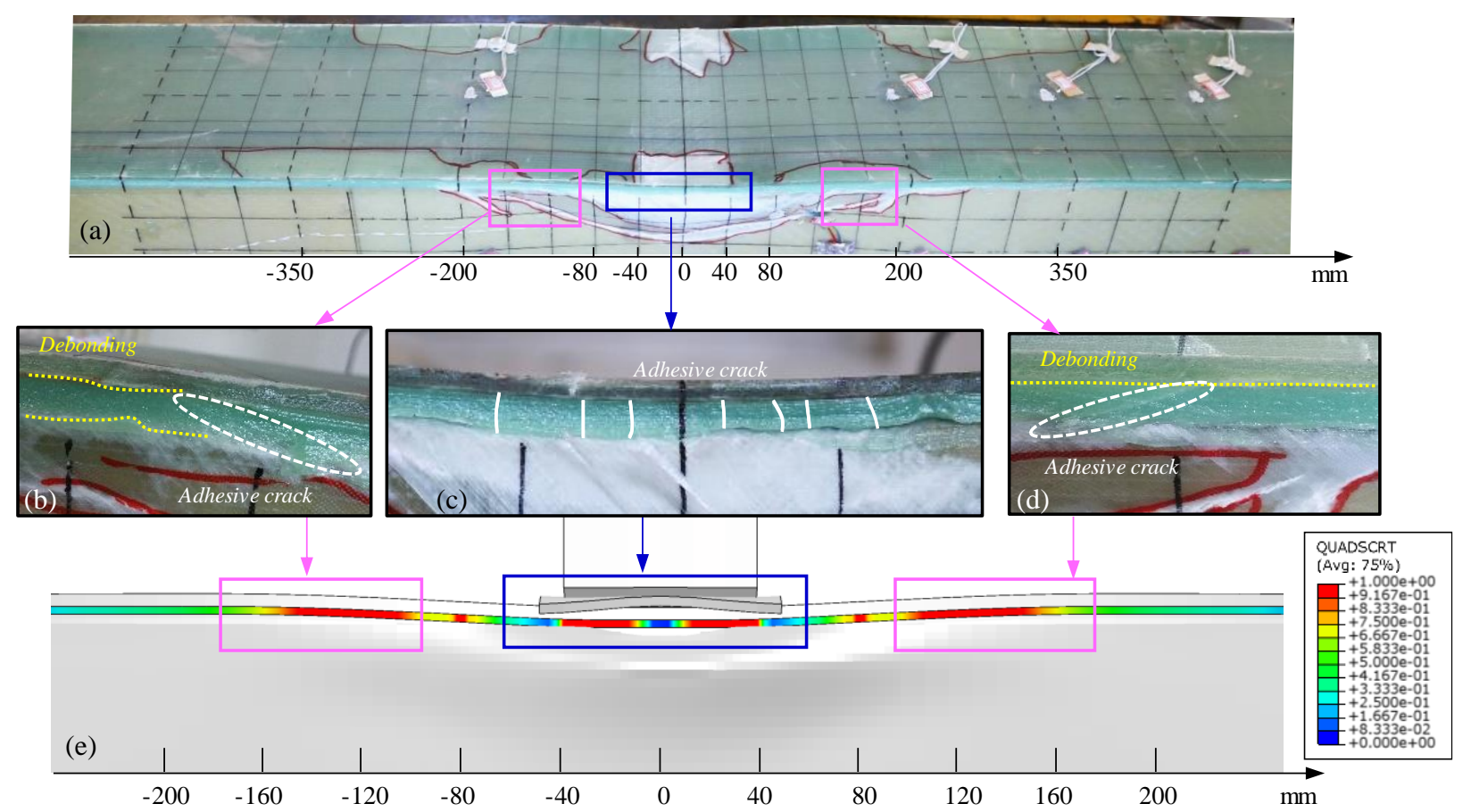

Figure 12. Comparison between the predicted and the observed final adhesive failure 


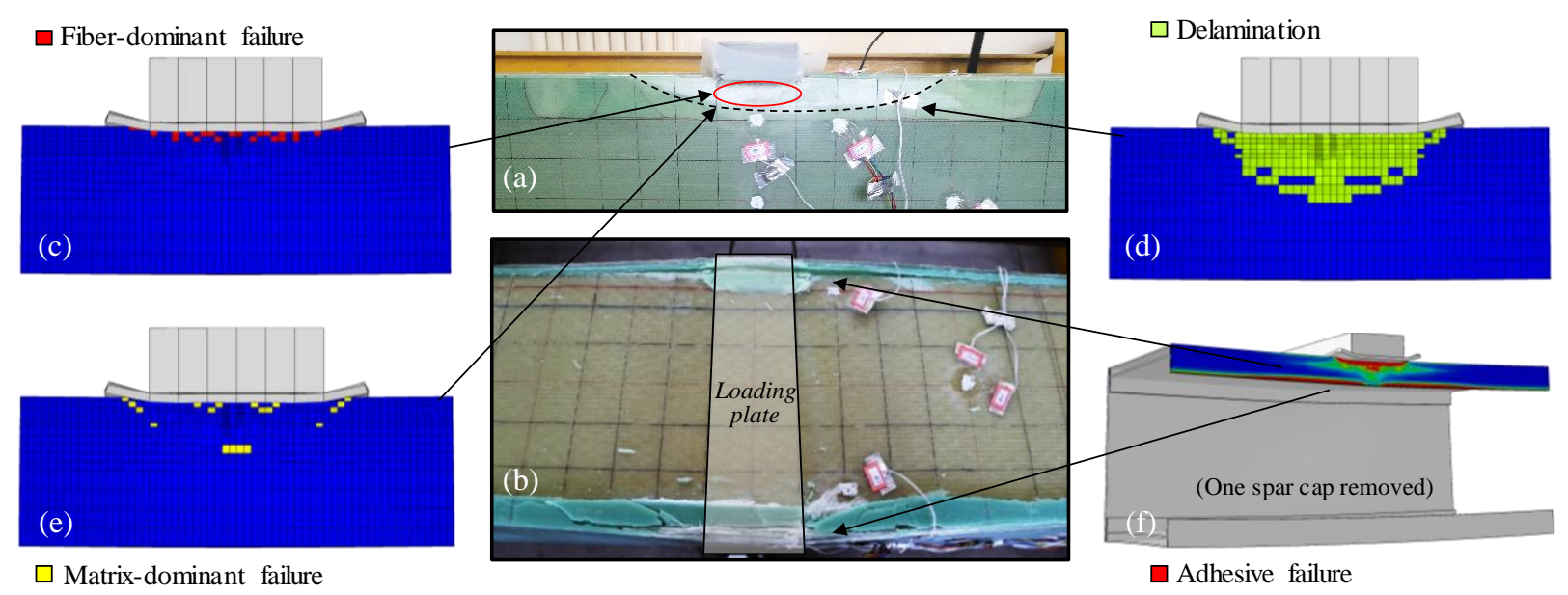

Figure 13. The final failure of the box beam under edgewise loading 

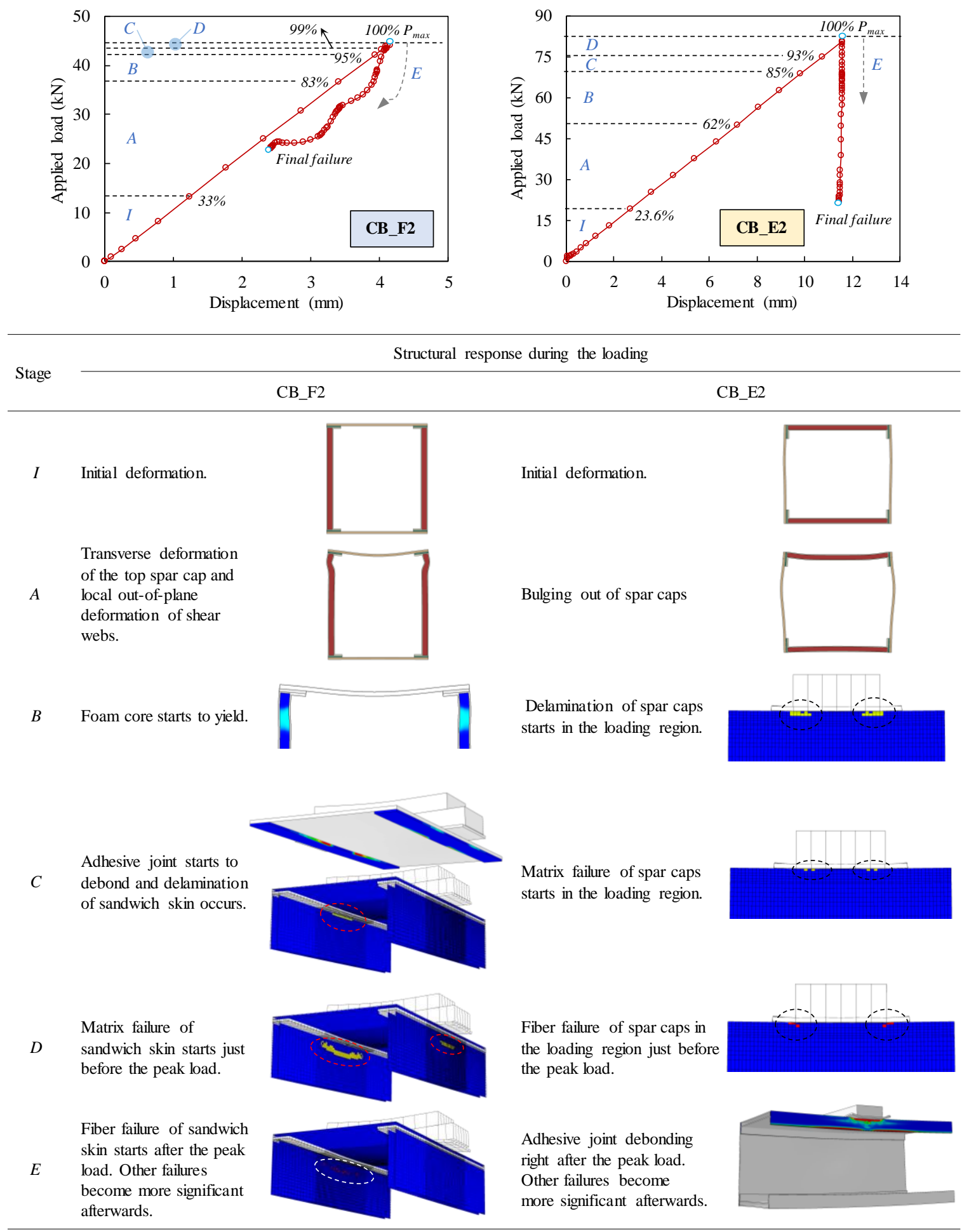

Figure 14. The predicted failure process of two box beams under different loading directions 


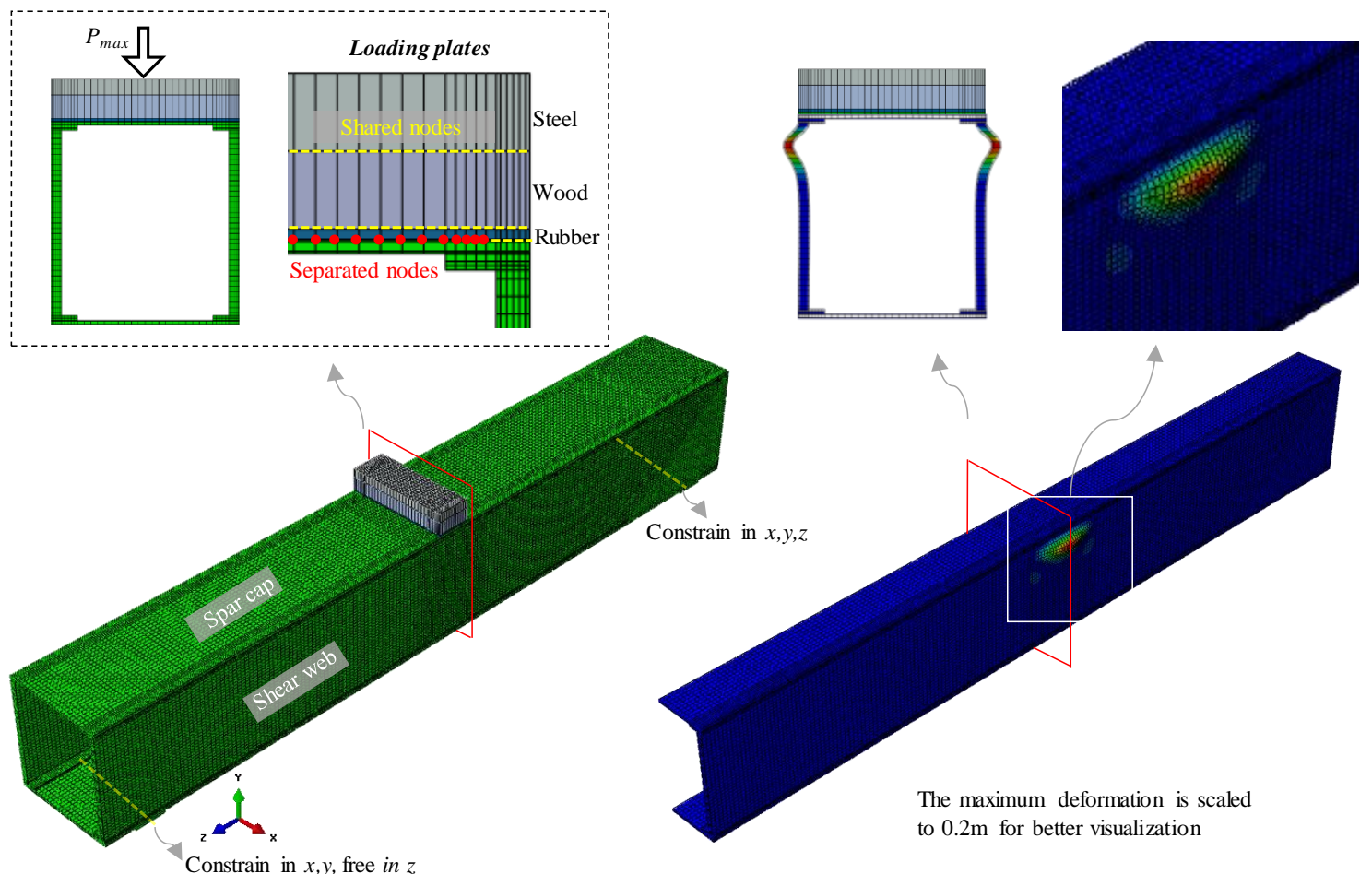

(a) The geometric model with local node connectivity

(b) The linear buckling mode shape used to generate geometric imperfections

Figure A1. The FE model used in the linear buckling analysis 